\title{
Hydroxyl Functionalized Methacrylic Terpolymers as Supports for Mn(III) Salen Catalysts and Their Application in Asymmetric Epoxidation
}

\author{
Katarzyna Matkiewicz • Agnieszka Bukowska • \\ Wiktor Bukowski
}

Received: 29 April 2011/ Accepted: 26 September 2011/Published online: 8 October 2011

(C) The Author(s) 2011. This article is published with open access at Springerlink.com

\begin{abstract}
Hydroxyl functionalized gel type resins derived from 2-hydroxyethyl, 2-hydroxypropyl and 2-hydroxy-3phenoxypropyl methacrylates were applied to covalent immobilization of $\mathrm{Mn}$ (salen) complexes via glutarate and carbonate linkers. The obtained catalysts were characterized by FTIR and DR UV-Vis methods and elemental analysis. It was found that the activity of polymeric catalysts obtained in this way depended on both the nature of the functional and cross-linking monomers and the degree of the cross-linking of polymer matrices and the way of complex immobilization. The highest activity was observed for the complexes immobilized on the HEMA resins crosslinked with 3\%-mol of diethylene glycol dimethacrylate. For instance, in the presence of the catalysts with $(\mathrm{S}, \mathrm{S})$ salen ligand $\mathrm{S}$-epoxystyrene and (1S, 2R)-epoxyindene could be obtained with $46 \%$ and $69 \%$ ee, respectively. Attempts have also been made to recycle the selected catalyst. However, a rapid fall off in the activity was observed, although the selectivity was similar in which three cycles.
\end{abstract}

Keywords 2-Hydroxyalkyl methacrylate gel type resins . $\mathrm{Mn}$ (salen) complexes · Polymer supported catalysts ·

Asymmetric epoxidation

\section{Introduction}

The asymmetric epoxidation of olefins is one of the most powerful methods of synthesis of intermediates which are used for synthesis of large variety of pharmaceuticals and

K. Matkiewicz · A. Bukowska · W. Bukowski $(\bowtie)$

Faculty of Chemistry, Rzeszow University of Technology, Al.

Powstańców W-wy 6, 35-959 Rzeszów, Poland

e-mail:wbuk@prz.edu.pl other biologically active compound [1]. The milestone in this topic was the development by Jacobsen and co workers [2] and Katsuki and co workers [3] the highly active chiral catalysts based on manganese salen complexes, described firstly in 1990. A consequence of their discoveries was hundreds papers focused on the tuning of $\mathrm{Mn}$ (salen) complexes and their application as catalysts in asymmetric epoxidations different groups of olefins which were published till now. They were summarized in several reviews [4-8]. Different protocols of the asymmetric epoxidation in the presence of $\mathrm{Mn}$ (salen) catalysts were explored from which the most common are the use of m-CPBA/NMO and $\mathrm{NaOCl} / \mathrm{PPNO}$ systems.

In the last decade, major efforts have been directed toward the development of new catalytic systems which combine the advantages of heterogeneous and homogeneous catalysis [1]. Many types of carriers, both inorganic and organic, soluble and insoluble, and different ways of immobilization of salen complexes (covalent, coordinate, ionic or physical bonding) were explored for catalytic purposes [8-13]. It was found that through the connection of a complex with supports which provide the sufficient mobility of catalytic active species and/or the good accessibility of reagents to catalytic centers is possible to obtain heterogeneous catalysts which the activity and the selectivity are comparable to homogenous analogous. Additionally, they would be easily recoverable and potentially recyclable. In the case of asymmetric epoxidation it was partially attained, for instance, by Janda and Reger [14] and Smith et al. [15]. The catalysts obtained by them were characterized by the activity and selectivity comparable with homogenous catalysts in epoxidation substituted olefins.

In this work the usefulness of the gel type resins derived from easily available 2-hydroalkyl methacrylates 
(2-hydroxyethyl, HEMA, 2-hydroxypropyl, HPMA, and 2-hydroxy-3-phenoxypropyl, PPMA) as supports for immobilization of Mn(salen) complex catalysts and their catalytic activity in asymmetric epoxidation of styrene (and its derivatives) were explored.

\section{Experimental}

\subsection{Reagents}

2-Hydroxyethyl methacrylate (HEMA, 97\%, SigmaAldrich) was distilled under reduced pressure before use. Styrene (S, 99\%, Sigma-Aldrich), divinylbenzene (DVB, $80 \%$, Fluka mixture of isomers), 2-hydroxypropyl methacrylate (HPMA, mixture of isomers, Fluka), triethylene glycol dimethacrylate (TEGDMA, 95\%, Sigma-Aldrich), diethylene glycol dimethacrylate (DEGDMA, 95\%, SigmaAldrich) were purified from inhibitors by extraction with $5 \mathrm{wt} \% \mathrm{NaOH}$ in $20 \mathrm{wt} \% \mathrm{NaCl}$ solution. 3,5-Di-tert-butylsalicylaldehyde and 3-tert-butyl-5-hydroxysalicylaldehyde were synthesized according to the procedures described by Jacobsen et al. [16, 17]. 2-Hydroxy-3-phenoxypropyl methacrylate was prepared in the reaction of phenyl glycidyl ether with methacrylic acid in the presence of chromium(III) acetate [18]. Glutaric anhydride (GA, 95\%, Sigma-Aldrich), 4-nitrophenyl chloroformate (NCF, 96\%, Sigma-Aldrich), 4-dimethylaminopyridine (DMAP, 98\%, Fluka), N-methylmorpholine N-oxide (NMO, 97\%, Sigma-Aldrich), $m$-chloroperbenzoic acid ( $m$-CPBA, Sigma-Aldrich) and manganese(II) acetate tetrahydrate were purchased from Fluka ( $>99 \%)$. Other reagents and solvents purchased from $\mathrm{POCH}$, Fluka or Aldrich were used as obtained.

\subsection{Catalysts Synthesis}

\subsubsection{Synthesis of Polymeric Supports 1.1-8}

The polymers used as matrices for preparation of the catalysts 6.1-8-7.1-7 were obtained in a consequence of suspension polymerization of the mixture of 2-HEMA or 2-HPMA or 2-hydroxy-3-phenoxypropyl (PPMA) methacrylates with styrene and DVB or DEGDMA or TEGDMA using the procedure described previously [19]. The polymerization was carried out in a $800 \mathrm{~mL}$ cylindrical reactor equipped with a heating coat, a mechanical stirrer, a reflux condenser and an addition funnel. The dispersion medium was prepared by dissolving $1 \mathrm{wt} \%$ polyvinylpyrrolidone K90 (PVP) in deionized water. The organic phase comprised benzoyl peroxide (BPO) (1 wt $\%$ ) dissolved in the mixture of monomers and cyclohexanol/n-octanol $4 / 1 \mathrm{w} / \mathrm{w}$ solvent system taken in $1 / 1 \mathrm{w} / \mathrm{w}$ proportion. This solution was added dropwise into the dispersion medium for about $30 \mathrm{~min}$. The polymerization was carried out under nitrogen atmosphere for $2 \mathrm{~h}$ at $70{ }^{\circ} \mathrm{C}$ and then for $6 \mathrm{~h}$ at $80^{\circ} \mathrm{C}$. The mechanical stirrer rate was adjusted to $350 \mathrm{rpm}$. After cooling of the reaction mixtures the spherical beads formed as a result were washed many times with water and then they were transferred to a Soxhlet apparatus and extracted with acetone for minimum $6 \mathrm{~h}$. After that time the beads of products were re-suspended in methanol, filtered off, dried under reduced pressure at $40{ }^{\circ} \mathrm{C}$ and then fractionized using sieves to isolate the fraction with diameter in a range of $75-150 \mu \mathrm{m}$. To determine the loadings of $\mathrm{OH}$ groups the small samples $(0.2 \mathrm{~g})$ of the resins were transformed to their 4-nitrophenyl carbonate derivatives similarly as was described previously [19]. The results of nitrogen analysis were used to assess the content of convertible $\mathrm{OH}$ groups.

The compositions of the monomers used for polymerization, the appropriate codes and the loadings of the resins are set in Tables 1 and 2. The simplified formula of hydroxyl functionalized resins $1.1-1.8$ is presented in Scheme 1. The results of elemental analysis for the resin 1.1: found \% C 80.37, H 7.768 (calcd. \%: C 81.74, H 7.67).

\subsubsection{Synthesis of Resins 2.1-8}

To obtain the 4-nitrophenyl carbonate derivatives 2.1-8 the resins 1.1-8 (2-3 g) were treated with 4-nitrophenyl chloroformate (10 eq) in the presence of triethylamine (5 eq). The modifications were performed in glass cylindrical reactors in a medium of dry methylene chloride $(10-15 \mathrm{~mL} / \mathrm{g}$ of a resin). The mixtures were shaken for $24 \mathrm{~h}$ at room temperature. Polymer products derived in this way were then filter off and rinsed several times with a mixture of methylene chloride and methanol to remove an excess reagent and other impurities. The final products were dried under the reduced pressure at $40{ }^{\circ} \mathrm{C}$. The yields of esterification were assessed on the base of the analysis of nitrogen percentages. The full elemental analysis for the resin 2.1 was also carried out: found \% C 75.13, H 6.614, N $1.543, \mathrm{C} / \mathrm{N}$ ratio $=48.70($ calcd. \%: $\mathrm{C} 76.09, \mathrm{H} 6.71, \mathrm{~N}$ $1.56, \mathrm{C} / \mathrm{N}$ ratio $=48.78)$.

\subsubsection{Synthesis of Resins 3.1-7}

To obtain the monoglutarate derivatives 3.1-7 the resins 1.1-7 (2-3 g) were reacted with glutaric anhydryde (GA, $2.1 \mathrm{eq})$ in the presence of DMAP (2.2 eq) in dry methylene chloride (10-15 mL/gram of a resin). The syringe-type reactors $(50-100 \mathrm{~mL})$, equipped with Luer valves placed on a horizontal vibratory shaker, were used. The reactions were performed at room temperature for $24-48 \mathrm{~h}$. After that time the resins were filtered off, rinsed with a solution of acetic acid in methylene chloride $(1 / 4 \mathrm{v} / \mathrm{v})$ and then 
Table 1 Compositions of monomers for synthesis of hydroxyalkyl resins

\begin{tabular}{|c|c|c|c|c|c|c|c|}
\hline \multirow[t]{2}{*}{ Terpolymer } & \multicolumn{7}{|c|}{ Monomers \%mol (g) } \\
\hline & HEMA & HPMA & PPMA & DEGDMA & TEGDMA & DVB & $\mathrm{S}$ \\
\hline 1.1 & $20(14.91)$ & - & - & $3(4.16)$ & - & - & $77(45.93)$ \\
\hline 1.2 & $20(14.55)$ & - & - & $5(6.77)$ & - & - & $75(43.67)$ \\
\hline 1.3 & $20(13.74)$ & - & - & $10(12.79)$ & - & - & $70(38.48)$ \\
\hline 1.4 & $20(12.35)$ & - & - & $20(22.99)$ & - & - & $60(29.65)$ \\
\hline 1.5 & $20(14.74)$ & - & - & - & $3(4.86)$ & - & $77(45.40)$ \\
\hline 1.6 & $20(15.36)$ & - & - & - & - & $3(2.88)$ & $77(47.33)$ \\
\hline 1.7 & - & $20(16.12)$ & - & $3(4.06)$ & - & - & $77(44.82)$ \\
\hline 1.8 & - & - & $20(22.78)$ & $3(3.51)$ & - & - & 77 (38.69) \\
\hline
\end{tabular}

Table 2 Synthesis of hydroxyalkyl of resins and their 2-nitrophenyl and monoglutarate derivatives

\begin{tabular}{|c|c|c|c|c|c|c|c|c|c|c|}
\hline \multirow[t]{2}{*}{ Resin } & \multicolumn{4}{|l|}{ Terpolymer } & \multicolumn{3}{|c|}{ Esterification with $\mathrm{NCF}$} & \multicolumn{3}{|c|}{ Esterification with GA } \\
\hline & $\begin{array}{l}\text { Functional monomer } \\
(\% \mathrm{~mol})\end{array}$ & $\begin{array}{l}\text { Cross-linking } \\
\text { monomer }(\% \mathrm{~mol})\end{array}$ & $\begin{array}{l}\text { Styrene } \\
(\% \text { mol })\end{array}$ & $\begin{array}{l}L_{O H}^{\mathrm{a}} \\
\left(\mathrm{mmol} \mathrm{g}^{-1}\right)\end{array}$ & Resin & $\% \mathrm{~N}^{\mathrm{b}}$ & $\begin{array}{l}\text { Yield } \\
(\%)\end{array}$ & Resin & $\begin{array}{l}L_{\mathrm{COOH}}^{\mathrm{c}} \\
\left(\mathrm{mmol} \mathrm{g}^{-1}\right)\end{array}$ & $\begin{array}{l}\text { Yield } \\
(\%)\end{array}$ \\
\hline 1.1 & $20 \%$ HEMA & $3 \%$ DEGDMA & 77 & 1.36 & 2.1 & 2.02 & 100 & 3.1 & 1.42 & 91 \\
\hline 1.2 & & $5 \%$ DEGDMA & 75 & 1.34 & 2.2 & 1.96 & 100 & 3.2 & 1.21 & 81 \\
\hline 1.3 & & $10 \%$ DEGDMA & 70 & 1.27 & 2.3 & 1.86 & 100 & 3.3 & 1.13 & 80 \\
\hline 1.4 & & $20 \%$ DEGDMA & 60 & 1.29 & 2.4 & 1.49 & 100 & 3.4 & 0.92 & 82 \\
\hline 1.5 & & $3 \%$ TEGDMA & 77 & 1.34 & 2.5 & 1.97 & 99 & 3.5 & 1.42 & 96 \\
\hline 1.6 & & $3 \%$ DVB & & 1.45 & 2.6 & 1.74 & 100 & 3.6 & 1.46 & 99 \\
\hline 1.7 & $20 \%$ HPMA & 3\% DEGDMA & & 1.17 & 2.7 & 1.66 & 100 & 3.7 & 0.56 & 45 \\
\hline 1.8 & $20 \%$ PPMA & 3\% DEGDMA & & 1.40 & 2.8 & 1.09 & 68 & - & - & \\
\hline
\end{tabular}

${ }^{a}$ Loadings of $\mathrm{OH}$ groups

b Nitrogen percentage obtained by Kjeldahl method

${ }^{c}$ Loadings of $\mathrm{COOH}$ groups

Scheme 1 Routes of preliminary modification of the hydroxyalkyl resins

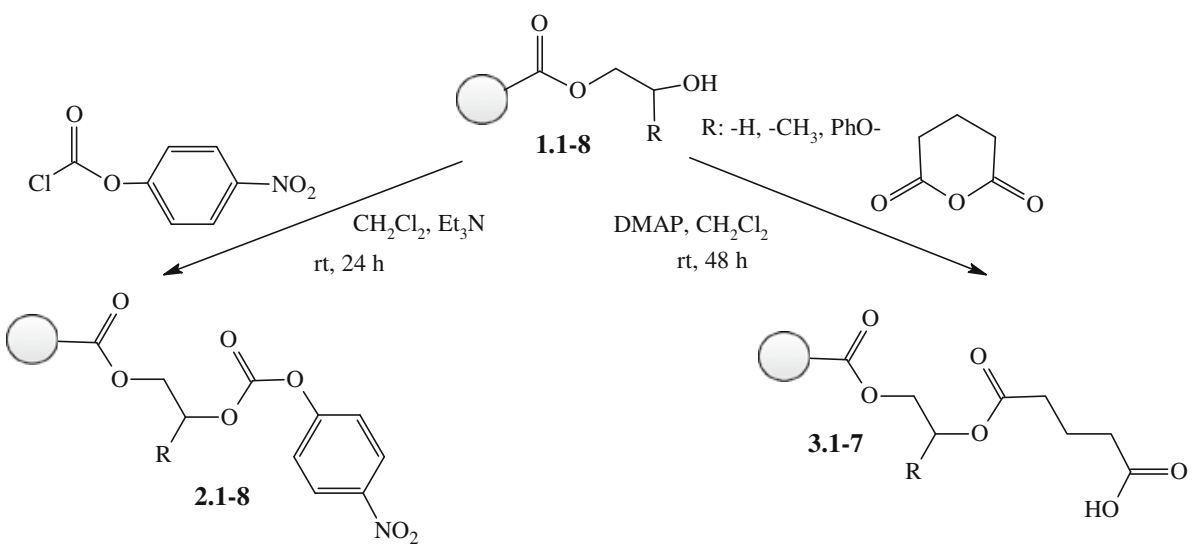

washed as in the case of 4-nitrophenyl carbonate resins. Products were dried under the reduced pressure at $40{ }^{\circ} \mathrm{C}$. The yields of esterification were assessed on the base of analysis of available carboxylic groups. The full elemental analysis for the resin $\mathbf{3 . 1}$ was also carried out: found \% $\mathrm{C}$ 77.13, H 7.538 (calcd. \%: C 77.83, H 7.35).

\subsubsection{Salen Ligand Immobilization}

The resins in the form of 4-nitrophenyl carbonates or monoglutarates (1-2 g) were coupled with hydroxyl functionalized salen 1 ((R,R)- or (S,S)-isomer, 2 eq) obtained separately according to the procedure described by 
Jacobsen et al. [20]. In the case of 2.1-8 $N, N$-diisopropylethylamine (DIPEA, 2 eq) and DMAP (1 eq) were used as co-reagents. The coupling of 1 with monoglutarate resins 3.1-7 were performed in the presence of $N, N^{\prime}$-dicyclohexylcarbodiimide (DCC, 2 eq) and DMAP (0.5 eq). All reactions were carried out in dry methylene chloride $(10-15 \mathrm{~mL} / \mathrm{g}$ of a resin). The reaction mixtures were agitated at room temperature for $48 \mathrm{~h}$. The yielded resins, 4.1-8 and 5.1-7 respectively, were rinsed with $\mathrm{CH}_{2} \mathrm{Cl}_{2}$ and $\mathrm{MeOH}$ repeatedly and dried under the reduced pressure at $40{ }^{\circ} \mathrm{C}$. The efficiency of immobilization was assessed on the base of nitrogen analysis. The full elemental analysis for the resin 4.1 was also carried out: found \% C 77.37, H 7.567, N $2.018, \mathrm{C} / \mathrm{N}$ ratio $=38.34($ calcd. \%: C 78.61, H 7.99, N $2.21, \mathrm{C} / \mathrm{N}$ ratio $=35.57)$.

\subsubsection{Synthesis of Salen Mn(III) complexes}

The resin 4.1-8 and 5.1-7 ( $0.3 \mathrm{~g})$ contained immobilized salen moieties were swelled in $1 \mathrm{~mL}$ of the mixture of $\mathrm{MeOH}$ and $\mathrm{CH}_{2} \mathrm{Cl}_{2}$ taken in $1 / 3 \mathrm{v} / \mathrm{v}$ proportion and the solutions of manganese(II) acetate (1 eq) in $1 / 3 \mathrm{v} / \mathrm{v}$ $\mathrm{MeOH}-\mathrm{CH}_{2} \mathrm{Cl}_{2}$ mixture were added). The mixtures were shaken for $1 \mathrm{~h}$ at room temperature and then the solutions of lithium chloride $(3 \mathrm{eq})$ in water $(0.1 \mathrm{~mL})$ were added. The shaking was continued for further $1.5 \mathrm{~h}$ with bubbling of the air into the mixtures. After that time the polymer products were filtered off, rinsed sequentially with $1 / 3 \mathrm{v} / \mathrm{v}$ $\mathrm{MeOH}-\mathrm{CH}_{2} \mathrm{Cl}_{2}$ mixture, $\mathrm{CH}_{2} \mathrm{Cl}_{2}$ and $\mathrm{MeOH}$ and dried under the reduced pressure. The catalysts 6.1-8 and 7.1-7 were obtained as dark brown beads. AAS analysis indicated $0.27-0.69 \mathrm{mmol} \mathrm{Mn} / \mathrm{g}$ of a resin. The full $\mathrm{CHN}$ analysis for the resin $\mathbf{6 . 1}$ was also carried out: found \% C 73.29, H 7.196, N 1.889, $\mathrm{C} / \mathrm{N}$ ratio $=38.81($ calcd. \%: $\mathrm{C}$ 73.48, H 7.33, $\mathrm{N} 2.06, \mathrm{C} / \mathrm{N}$ ratio $=35.67)$.

\subsection{Resin Characterization and Performed Analysis}

FT-IR studies of the resins were performed using Nicollet 8700 spectrometer and a standard $\mathrm{KBr}$ pellet technique. Diffuse reflectance UV-Vis (DR UV-Vis) spectra of the resin samples were recorded in Jasco V-670 spectrophotometer equipped with UV-Vis-NIR $60 \mathrm{~mm}$ integrating sphere Jasco ISN-723 using $\mathrm{BaSO}_{4}$ as standard. Manganese ions loadings in obtained catalysts was determining by AAS method using Perkin Elmer-3100 spectrophotometer at $\lambda_{\max }=279.5 \mathrm{~nm}$. Before analysis samples of the catalyst (10-20 mg) were mineralized in concentrated $\mathrm{HNO}_{3}$ $(5 \mathrm{~mL})$ using the microwave mineralizer Plazmatronika Uni Clever II. The samples for Kjeldahl analysis (16-18 mg) were mineralized in concentrated $\mathrm{H}_{2} \mathrm{SO}_{4}(2 \mathrm{~mL})$ in the presence of Kjeldahl catalyst using thermal mineralizer Velp Scientifica DK6 Heating Digester and then they were transferred to a classic Kjeldahl system to release ammonia to boric acid solution. The distillates were then titrated with $0.01 \mathrm{M} \mathrm{HCl}$ solution in the presence of the mixed indicator (the methyl red-bromkresol green mixture).

To determine the loadings of $\mathrm{COOH}$ groups samples $(0.1 \mathrm{~g})$ of the resins 3.1-7 swelled in $10 \mathrm{~mL}$ acetone were treated with an excess of $\mathrm{NaOH}$ solution $(20 \mathrm{~mL}, 0.1 \mathrm{M})$ in syringe-type reactors equipped with Luer valves and rubber septa with needles. The mixtures were shaken for $6 \mathrm{~h}$ at room temperature and then an excess $\mathrm{NaOH}$ solution was removed. The samples were rinsed several times with small portions of the mixed solvent acetone-water $(2 / 1 \mathrm{v} / \mathrm{v}$, $\sim 20 \mathrm{~mL}$ ). Collected filtrates were titrated with $0.1 \mathrm{M} \mathrm{HCl}$ solution. The results of analysis were applied for calculation of $\mathrm{COOH}$ group content.

GC analysis of reaction was carried out using Agilent 7980A system equipped with a split-splitness injector, FID detector, HP-FFAP column $(30 \mathrm{~m} \times 0.30 \mathrm{~mm} \times 0.25 \mu \mathrm{m})$ and ChemStation. The enantiomeric excess (\% ee) of products of epoxidation was determined by HPLC method using Agilent 1100 system equipped with a quaternary pump, a degasser, DAD detector (R,R)-Whelk-O 1 column $(25 \mathrm{~cm} \times 4.6 \mathrm{~mm})$ and ChemStation.

\subsection{Catalytic Tests}

Styrene or its derivatives (1 eq) and NMO (5 eq.) were dissolved in $\mathrm{CH}_{2} \mathrm{Cl}_{2}$ (8 $\mathrm{mL} / 1 \mathrm{mmol}$ olefine) and the polymer catalyst 6.1-8 or 7.1-7 (4\%-mol Mn) was added. The mixture was cooled to $-78^{\circ} \mathrm{C}$ in an acetone-dry ice bath. Solid $m$-CPBA ( $2 \mathrm{eq}$ ) in four roughly equal portions was added over two min periods. The progress of reaction was monitored by GC analysis. The reaction mixture was stirred at $-78{ }^{\circ} \mathrm{C}$ for $5 \mathrm{~h}$. After completing of reactions the catalysts were filtered off, washed from reagents with methanol and methylene chloride and once more with methanol. Filtrates were collected and washed with $1 \mathrm{M}$ $\mathrm{NaOH}(2 \times 20 \mathrm{~mL})$ and brine. The organic layer was dried over anhydrous $\mathrm{MgSO}_{4}$ and concentrated under the reduced pressure. The enantiomeric excess of epoxides was determined by HPLC method.

\section{Results and Discussion}

\subsection{Preparation of the Catalysts}

The preparation of polymer supported salen manganese(III) catalysts included the synthesis of hydroxyl functionalized resins called further as HEMA, HPMA and PPMA resins (Scheme 1). They were obtained in the form of spherical beads by suspension polymerization of the mixtures of 2-HEMA or 2HPMA or 2-hydroxy-PPMA with styrene and 
a divinyl monomer (DVB, DEGDMA or TEGDMA) (Table 1). The procedure described previously for synthesis of the HEMA resins turned out to be also useful in the case of synthesis of the HPMA and PPMA resins [19]. The loadings of the resins ranged from 1.17 to $1.45 \mathrm{mmol}$ of $\mathrm{OH}$ groups/g. They were determined according to the procedure described in the previous work [19].

The $\mathrm{OH}$ functionalized resins were then converted to 4-nitrophenyl carbonate or monoglutarate forms in the reactions with an excess of 4-nitrophenyl chloroformate or glutaric anhydride, respectively, similarly to the work [21]. The efficiency of modification was assessed by FTIR method. It was found that in applied conditions the most alcoholic groups of HEMA, HPMA and PPMA resins was converted to ester ones. As a proof of that the lowering of absorption in the region characteristic of hydroxyl groups was observed. The broadening of absorption bands, in the ranges of absorption of carbonyl and hydroxyl groups proved the incorporation of carboxylic groups into the polymer matrices $\left(\sim 3500 \mathrm{~cm}^{-1}(\mathrm{OH}), \sim 1730(\mathrm{C}=\mathrm{O})\right.$ (Fig. 1). The formation of 4-nitrophenyl carbonates was accompanied with appearing of additional absorption bands at $1770(\mathrm{C}=\mathrm{O}), 1530\left(-\mathrm{NO}_{2}\right), 1350\left(-\mathrm{NO}_{2}\right)$ and $860 \mathrm{~cm}^{-1}\left(-\mathrm{NO}_{2}\right)$ (Fig. 1).

The quantitative modification degrees were estimated from the percentage of nitrogen in 4-nitrophenyl carbonate resins, on the one side, and the loading of $\mathrm{COOH}$ groups in monoglutarate resins determined by a titration method, on the other. It was found that under the influence of 4-nitrophenyl chloroformate in the most cases the hydroxyalkyl resins were converted to 4-nitrophenyl formate forms quantitatively (Table 2). Only for the PPMA resin the modification degree amounted $68 \%$. The modification of the hydroxyalkyl resins to monoglutarate resins carried out less efficiently and it depended on both the cross-linking degree of the polymer matrices and the nature of cross-linkers. They yield of modification decreased with increasing in the nominal cross-linking degrees what clearly indicated difficulties in the accessibility of $\mathrm{OH}$ group for homogeneous reagents in the case of more cross-linked resins (Table 2).

The immobilization of salen ligands via carbonate linkers (2.1-8) was carried out analogously to Jacobsen work [22]. The esterification of the monoglutarate resins (3.1-7) was performed at room temperature in the presence of $\mathrm{N}, \mathrm{N}^{\prime}-$ dicyclohexylcarbodiimide (DCC) or $\mathrm{N}, \mathrm{N}^{\prime}$-diisopropylcarbodiimide (DIC) as a dehydrating agent (Scheme 2). The conversion of $\mathrm{COOH}$ groups estimated from the analysis of nitrogen percentage in products amounted from $53.3 \%$ for HPMA (5.7) to $99.0 \%$ for HEMA (4.1) (Table 3). The asymmetrically substituted chiral salen ligands $\mathbf{1}$ (R,R or $\mathbf{S , S )}$ are easily available from the mixed condensation of R,R- or S,S-trans-1,2-diaminocyclohexane (2 eq), 3-tert-butyl-5-hydroxysalicylaldehyde (1 eq) and 3,5-ditert-butylsalicylaldehyde ( $3 \mathrm{eq})$ and they can be used for immobilization without additional purification [22].

The incorporation of salen moieties into polymer matrices was accompanied with an appearance of absorption bands at $1630 \mathrm{~cm}^{-1}$ characteristic of imine groups. In the case of the transformation of 4-nitrophenyl carbonate resins a disappearance of absorption bands related to $\mathrm{NO}_{2}$ groups at 1530,1350 and $860 \mathrm{~cm}^{-1}$ was additionally observed in the spectra of products. The coupling of $\mathbf{1}$ with carboxylic groups resulted additionally in changes in absorption in a range characteristic of $\mathrm{COOH}$ groups at above $3200 \mathrm{~cm}^{-1}$ (OH acidic) as well.
Fig. 1 The comparison of FTIR spectra of resin $\mathbf{1 . 1}$ and products of its modification

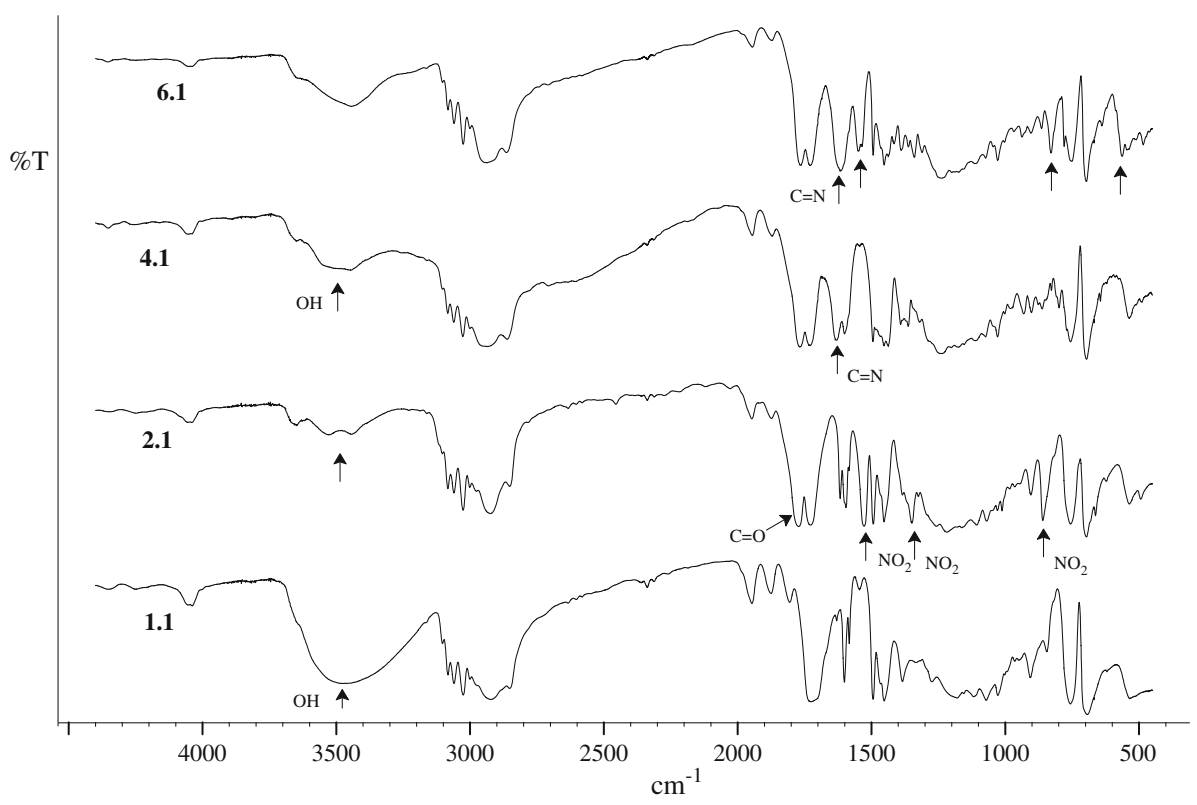


Manganese(III) ions were introduced into the salen bearing resins in a consequence of their treating with a solution of $\mathrm{Mn}(\mathrm{II})$ acetate in methanol-methylene chloride $(1 / 3 \mathrm{v} / \mathrm{v})$ followed by the addition of lithium chloride and bubbling of the air into reaction mixtures (Scheme 3). As a result the polymer bound $\mathrm{Mn}(\mathrm{III})$ (salen) complexes with loadings of $0.27-0.69 \mathrm{mmol} \mathrm{Mn} / \mathrm{g}$ were obtained (Table 3). The loading of manganese ions decreased when the nominal cross-linking degree of the resin increased. Taking into account the loadings of $\mathrm{Mn}$ ions and the yields of salen immobilization the efficiency of manganese complexing could be assessed. It was found that an increase in the cross-linking degree of the resins decreases in the yield of the complexing generally. On the other hand, there was observed rather the effect of the nature of crosslinking monomers on the complexing ability of the resins.

The polymer supported chiral catalysts were also characterized by FTIR spectra. Changes in absorption in the range typical of phenols, a shift of the $\mathrm{C}=\mathrm{N}$ band towards lower frequency (from 1630-1615 $\mathrm{cm}^{-1}$ ) and an appearance of new band at $530 \mathrm{~cm}^{-1}$ were found as a consequence of complexing of manganese ions by the immobilized salen moieties. The last bands are probable a consequence of the presence of $\mathrm{Mn}-\mathrm{N}$ or $\mathrm{Mn}-\mathrm{O}$ bonds in salen complexes [23]. In turn, the absorption bands at 1549 and $850 \mathrm{~cm}^{-1}$ which were also found in the spectra of catalysts indicates the presence of acetate forms of $\mathrm{Mn}$ (III) complexes (Fig. 1) [24].

The efficiency of immobilization of chiral Mn(III) salen complex on polymeric supports based on hydroxyl functionalized resins $\mathbf{1 . 1}$ was proved additionally by DR UVVis method. From the comparison of the spectra recorded for beads of polymeric catalyst $\mathbf{6 . 1}$ (spectrum d) with the spectra of parental HEMA resin $\mathbf{1 . 1}$ (spectrum a), 4-nitrophenyl carbonate derivative $\mathbf{2 . 1}$ (spectrum b) and polymer supported salen ligand $\mathbf{4 . 1}$ (spectrum c) one can easily conclude on changes in the chemical nature of the polymer support-the introduction of 4-nitrophenyl formate moieties, the substitution of 4-nitrophenoxy groups with hydroxyl substituted salen ligands and the complexing of manganese ions (Fig. 2). The spectra of catalyst $\mathbf{6 . 1}$ and salen precursor 4.1 exhibit similarity to the spectrum of free salen $\mathrm{Mn}(\mathrm{III})$ derived from chiral Jacobsen ligand (spectrum e). The absorption band at 244, 322 and $378 \mathrm{~nm}$ observed for the complex can be assigned to $\pi$-electron transfer transitions of salen ligand, the band at 440, 530 and $684 \mathrm{~nm}$ can be attributed to the ligand-to-metal charge transfer transition of $\mathrm{Mn}$ atom and the $\mathrm{d}-\mathrm{d}$-transitions of $\mathrm{Mn}$ atom. Similar spectra for free Mn(III) complexes and supported catalysts for asymmetric epoxidation were reported previously in works [25-27]).

\subsection{Catalytic Tests}

Polymer supported Mn(III)(salen) complexes 6 and 7 were tested as catalysts of asymmetric epoxidation of styrene (Scheme 4). m-CPBA and N-methylmorpholine N-oxide (NMO) were applied as an oxidation agent and an activator respectively. Reactions were performed in methylene chloride at $-78{ }^{\circ} \mathrm{C}$ using $4 \%$-mol of the catalysts in respect to styrene. The obtained results are presented in Table 4 and Figs. 3, 4, and 5.

It was found that the activity of salen Mn(III) complexes immobilized on the hydroxyalkyl methacrylate gels in asymmetric epoxidation of styrene strongly depended on the cross-linking of polymer matrices (Entry 1-6 and 11-16 in Table 4, Fig. 3). The resins of the higher nominal crosslinking degree showed the clearly lower activity as catalysts. Additionally, in the presence of these resins the lower enantiomeric excess of R-styrene oxide was obtained.

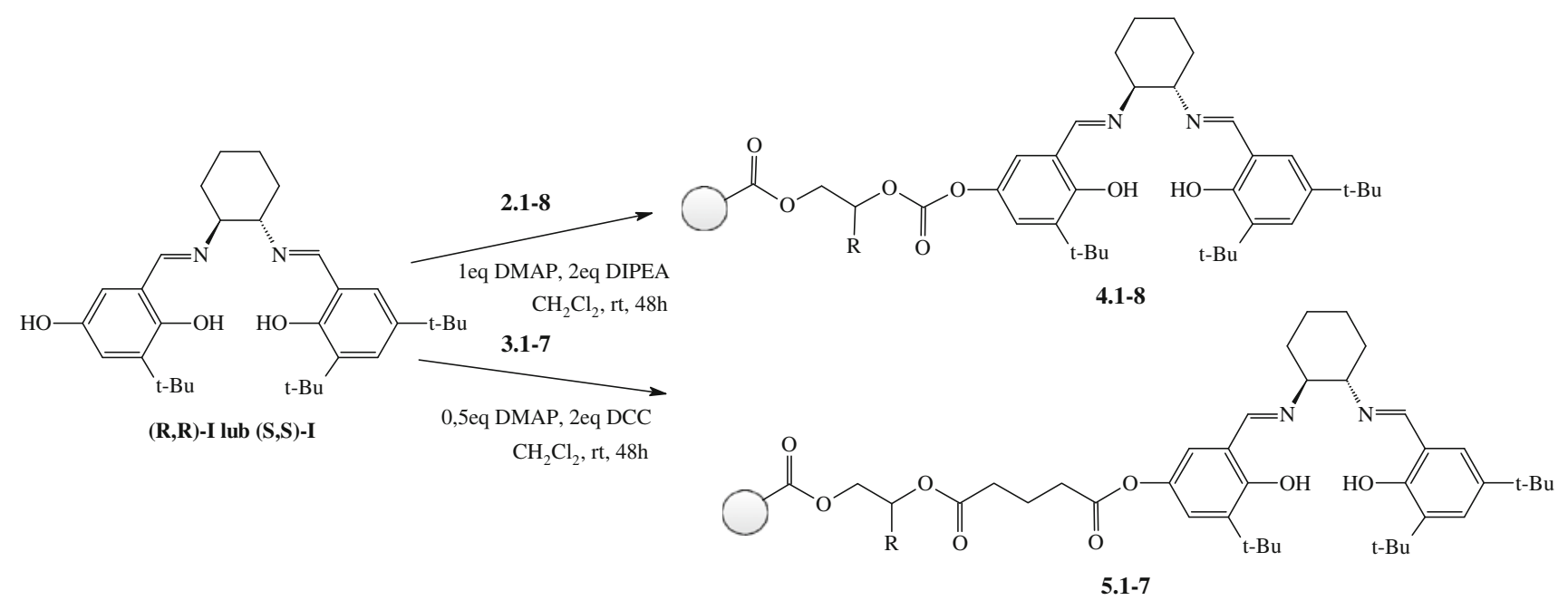

Scheme 2 Two routes of salen immobilization 
Table 3 Synthesis of polymer supported Mn(salen) catalysts and their precursors
${ }^{a}$ Nitrogen percentage obtained by Kjeldahl method

b Determined by AAS method after mineralizing of polymers

c Assessed based on Mn contents in polymer bound complexes and nitrogen percentages of polymer bound salens

\begin{tabular}{llllll}
\hline Resin & \% $\mathrm{N}^{\mathrm{a}}$ & $\begin{array}{l}\text { Yield of salen } \\
\text { immobilization, } \%\end{array}$ & $\begin{array}{l}\text { Mn(salen) } \\
\text { complex }\end{array}$ & $\begin{array}{l}\text { Mn content } \\
\mathrm{mmol} \mathrm{g}^{-1} \text { resin }\end{array}$ & $\begin{array}{l}\text { Yield of Mn } \\
\text { complexing }\end{array}$ \% \\
\hline 4.1 & 2.46 & 99 & $\mathbf{6 . 1}$ & 0.69 & 79 \\
$4.1(\mathrm{~S}, \mathrm{~S})$ & 2.39 & 91 & $\mathbf{6 . 1}(\mathbf{S}, \mathbf{S})$ & 0.69 & 81 \\
4.2 & 2.30 & 89 & $\mathbf{6 . 2}$ & 0.47 & 57 \\
4.3 & 2.16 & 87 & $\mathbf{6 . 3}$ & 0.55 & 71 \\
4.4 & 1.91 & 89 & $\mathbf{6 . 4}$ & 0.43 & 63 \\
4.5 & 2.14 & 82 & $\mathbf{6 . 5}$ & 0.63 & 83 \\
4.6 & 2.25 & 94 & $\mathbf{6 . 6}$ & 0.63 & 78 \\
4.7 & 1.58 & 86 & $\mathbf{6 . 7}$ & 0.52 & 93 \\
4.8 & 1.91 & 85 & $\mathbf{6 . 8}$ & 0.60 & 88 \\
5.1 & 1.91 & 72 & $\mathbf{7 . 1}$ & 0.56 & 78 \\
5.2 & 1.73 & 67 & $\mathbf{7 . 2}$ & 0.48 & 56 \\
5.3 & 1.67 & 67 & $\mathbf{7 . 3}$ & 0.33 & 51 \\
5.4 & 1.49 & 70 & $\mathbf{7 . 4}$ & 0.27 & 73 \\
5.5 & 2.07 & 80 & $\mathbf{7 . 5}$ & 0.54 & 68 \\
5.6 & 1.97 & 83 & $\mathbf{7 . 6}$ & 0.48 & 98 \\
5.7 & 1.23 & 53 & $\mathbf{7 . 7}$ & 0.43 & \\
\hline
\end{tabular}

Scheme 3 Metalation of polymer supported salen ligands

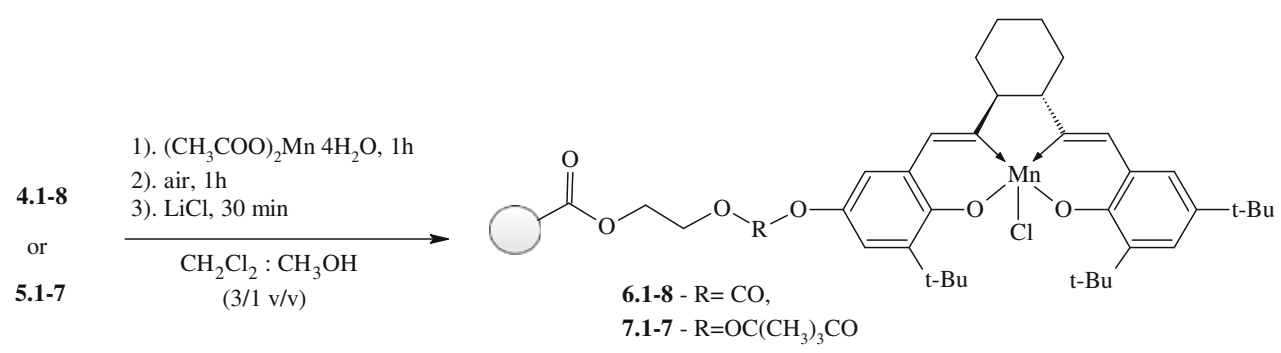

Fig. 2 DR UV-Vis spectra of resins $a$ 1.1, $b$ 2.1 $c$ 4.1,$d \mathbf{6 . 1}$ and $e$ Jacobsen $\mathrm{Mn}$ (III) complex

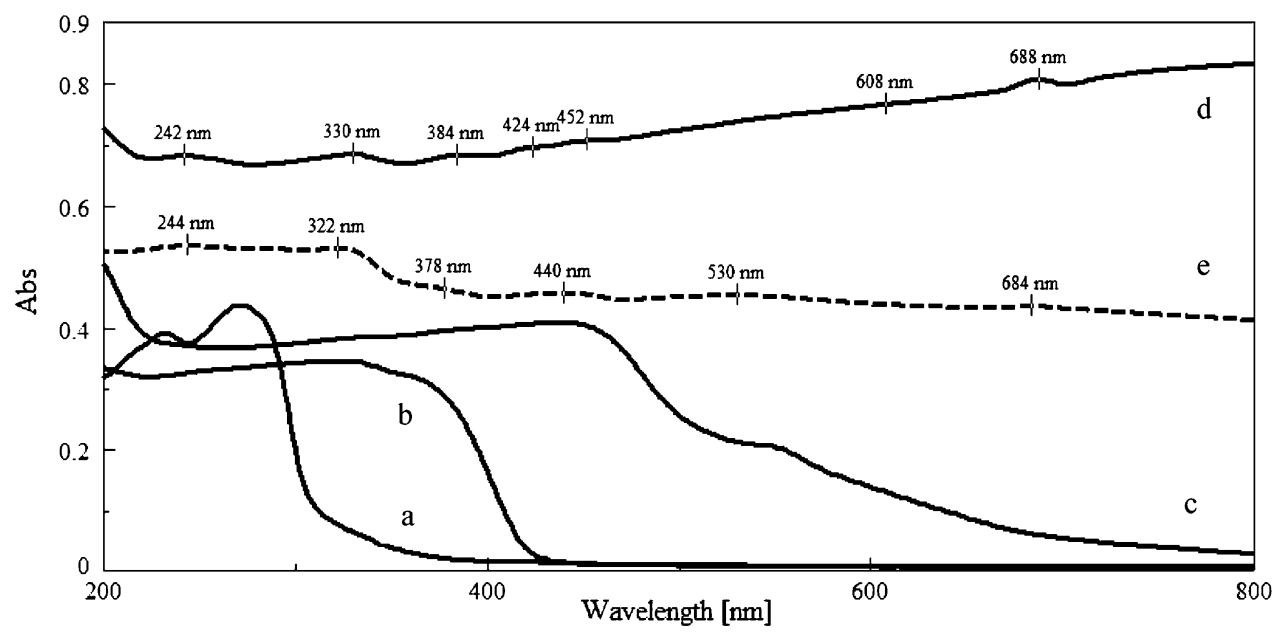

Similar findings were described earlier by De [28] and Sherrington et al. [29] for salen catalysts supported on macroporous resins. In the case of gel type resins an improvement in the catalytic activity and in the enatioselectivity can be achieved by lowering of the cross-linking of polymer matrices.
An influence of the nature of the cross-linkers on the activity of the catalysts and the selectivity of epoxidation was also observed. The higher enantioselectivity was found for the catalysts obtained in a consequence of immobilization of $\mathrm{Mn}$ (III) salen complex onto 2-HEMA terpolymers cross-linked with DEGDMA (e.g. Entry 1) compared with 


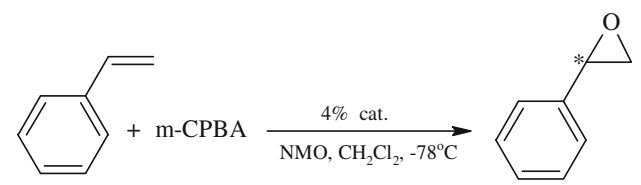

(a)

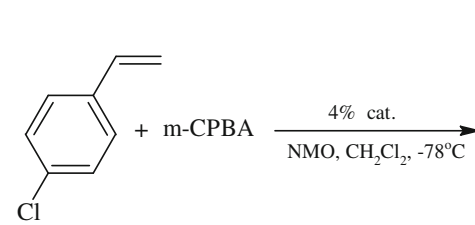<smiles>Clc1ccc(C2CO2)cc1</smiles>
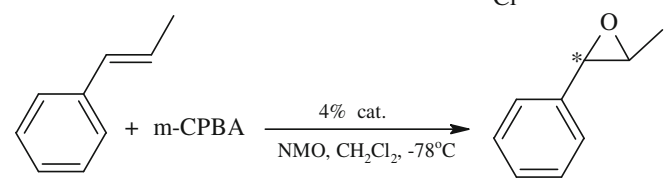

(c)

(b)

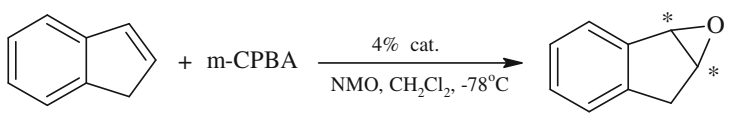

(d)

Scheme 4 Asymmetric epoxidation of olefins: $a$ styrene. $b$ 4-chlorostyrene, $c$ trans- $\beta$ - methylstyrene $d$ indene

Table 4 Results of epoxidation of styrene

\begin{tabular}{llll}
\hline Entry & Catalyst & $\begin{array}{l}\text { Conversion } \\
\text { of styrene }^{\mathrm{a}}(\%)\end{array}$ & $\mathrm{Ee}^{\mathrm{b}}(\%)$ \\
\hline 1 & $\mathbf{6 . 1}(1$ cycle $)$ & 82 & $42(\mathrm{R})$ \\
2 & $(2$ cycle $)$ & 65 & $39(\mathrm{R})$ \\
3 & $\mathbf{6 . 1}(\mathbf{S , S})$ & 92 & $46(\mathrm{~S})$ \\
4 & $\mathbf{6 . 2}$ & 44 & $29(\mathrm{R})$ \\
5 & $\mathbf{6 . 3}$ & 44 & $21(\mathrm{R})$ \\
6 & $\mathbf{6 . 4}$ & 22 & $11(\mathrm{R})$ \\
7 & $\mathbf{6 . 5}$ & 68 & $33(\mathrm{R})$ \\
8 & $\mathbf{6 . 6}$ & 48 & $27(\mathrm{R})$ \\
9 & $\mathbf{6 . 7}$ & 56 & $26(\mathrm{R})$ \\
10 & $\mathbf{6 . 8}$ & 78 & $40(\mathrm{R})$ \\
11 & $\mathbf{7 . 1}(1$ cycle $)$ & 79 & $39(\mathrm{R})$ \\
12 & $(2$ cycle $)$ & 68 & $40(\mathrm{R})$ \\
13 & $(3$ cycle $)$ & 46 & $38(\mathrm{R})$ \\
14 & $\mathbf{7 . 2}$ & 41 & $26(\mathrm{R})$ \\
15 & $\mathbf{7 . 3}$ & 33 & $15(\mathrm{R})$ \\
16 & $\mathbf{7 . 4}$ & 25 & $19(\mathrm{R})$ \\
17 & $\mathbf{7 . 5}$ & 67 & $37(\mathrm{R})$ \\
18 & $\mathbf{7 . 6}$ & 75 & $39(\mathrm{R})$ \\
19 & $\mathbf{7 . 7}$ & 54 & $29(\mathrm{R})$ \\
\hline
\end{tabular}

${ }^{a}$ Determined by GC after $5 \mathrm{~h}$

b Determined by HPLC using a chiral column (R,R)-Whelk-O 1 after $5 \mathrm{~h}$, hexane-propan-2-ol (99.8:0.2)

ones cross-linked with DVB (e.g. Entry 8) or TEGDMA (e.g. Entry 7 in Table 4; Fig. 4).

Generally, the activity of the complexes supported on HEMA resins was higher than the activity of the catalysts

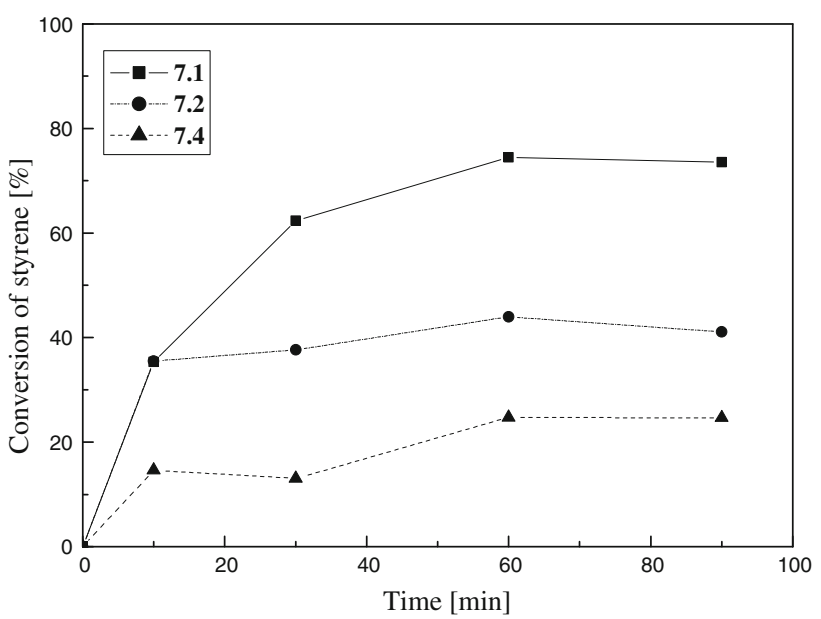

Fig. 3 The effect of the cross-linking on the activity of catalysts 7

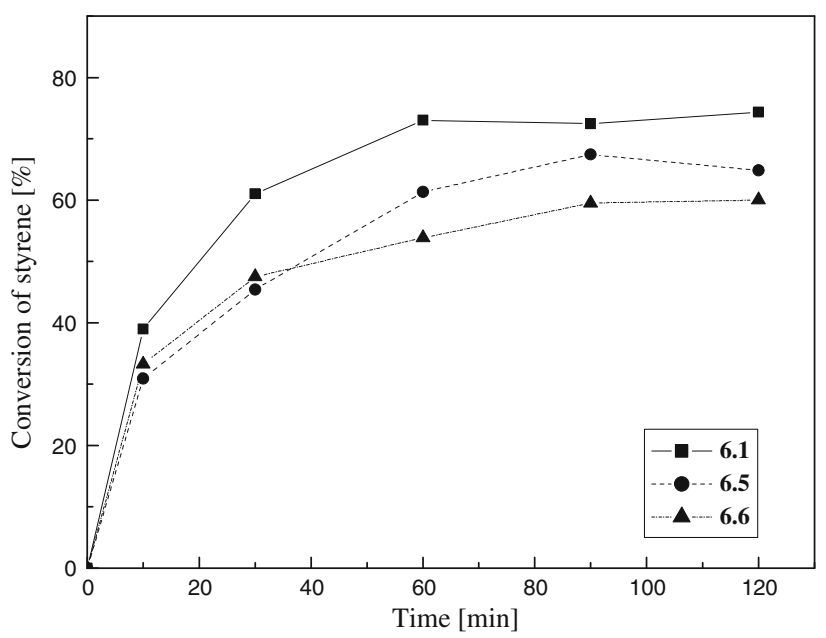

Fig. 4 The effect of the nature of cross-linkers on the activity of catalysts 6

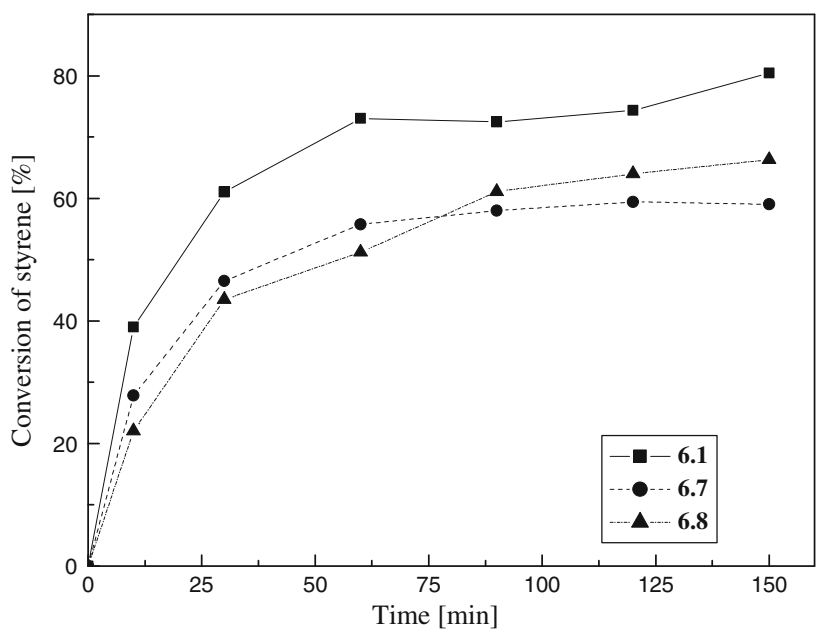

Fig. 5 The effect of the nature of functional monomers on the activity of catalysts 6 
Table 5 Results of asymmetric epoxidation

\begin{tabular}{lllll}
\hline Entry & Catalyst & Alkene & $\begin{array}{l}\text { Conversion } \\
(\%)\end{array}$ & $\mathrm{Ee}^{\mathrm{b}}(\%)$ \\
\hline 1 & $\mathbf{6 . 1}(\mathbf{R}, \mathbf{R})$ & 4-chlorostyrene & 79 & $28(\mathrm{R})$ \\
2 & & $\begin{array}{l}\text { trans- } \beta \text { - } \\
\text { methylstyrene }\end{array}$ & 33 & $9(\mathrm{R})$ \\
& & indene & 93 & $73(1 \mathrm{R}, 2 \mathrm{~S})$ \\
3 & $\mathbf{6 . 1 ( S , S )}$ & Indene & 76 & $69(1 \mathrm{~S}, 2 \mathrm{R})$ \\
\hline
\end{tabular}

${ }^{a}$ Determined by GC after $5 \mathrm{~h}$

${ }^{b}$ Determined by HPLC using a chiral column (R,R)-Whelk-O 1 after $5 \mathrm{~h}$, hexane-propan-2-ol (99.5:0.5)

based on HPMA (Entry 9) and PPMA (Entry 10) resins (Table 4; Fig. 5).

From all explored catalysts the complexes $\mathbf{6 . 1}$ obtained in a consequence of immobilization of salen moieties on the HEMA resin cross-linked with 3\%-mol of DEGDMA showed the highest catalytic activity (Entry 1,3). For instance, in the presence of catalyst 6.1(S,S) S-epoxystyrene was formed with $46 \%$ ee (Table 4). It was only slightly lower than the enantioselectivity of styrene epoxidation in the presence salen $\mathrm{Mn}(\mathrm{III})$ complexes immobilized on the JandaJel (51\% ee) [14] and comparable with the enantioselectivity found for the polymeric catalysts prepared by Zheng (36-51\% ee) [30].

The catalyst $6.1(\mathbf{R}, \mathbf{R})$ was additionally tested in asymmetric epoxidation of 4-chlorostyrene, trans- $\beta$-methylstyrene and indene (Scheme $4 \mathrm{~b}-\mathrm{d}$; Table 5). Compared with styrene, the epoxidation of its substituted derivatives went with the clearly lower enantioselectivity (28 and 9\% ee, respectively for 4-chlorostyrene and trans- $\beta$-methylstyrene). On the other side, the sufficiently higher enantioselectivity was observed for indene epoxidation (73\% ee). A slightly less enantiomeric excess of (1S,2R)epoxyindene (69\% ee) was obtained when the catalyst $\mathbf{6 . 1}$ (S,S) was applied for epoxidation. The obtained results are clearly better than those described by Sherrington and co workers [31] observed polystyrene and polymethacrylatebased resin supported chiral Mn salen complexes (33\% ee $(1 \mathrm{R}, 2 \mathrm{~S})$-indene oxide). However they are not such good as ones found by Kureshy et al. [32] for the catalysts obtained by immobilization of chiral $\mathrm{Mn}$ (III) salen complex on mesoporous materials such as MCM-41 (80\% ee) and SBA-15 (81\% ee).

Attempts of the recyclability of catalyst 6.1 and 7.1 in the reaction of epoxidation of styrene were carried out as well (Entry 1-2, 11-13 in Table 4). Unfortunately, a clear decrease in the activity of the catalyst was observed after each stage of recycling, although the enantioselectivity did not change for three cycles.

\section{Conclusion}

The new hydroxyalkyl resins supported chiral $\mathrm{Mn}(\mathrm{III})$ salen complex catalyst have been synthesized and applied for the epoxidation of a series of olefins. It was found that the activity of the catalysts increased remarkably with an increase in the nominal cross-linking degree of resins. The effect of the nature of the cross-linkers was also detected as playing an important role in the accessibility of reactants to catalytic centers. The complexes immobilized on the HEMA resin cross-linked with 3\%mol DEGDMA enabled to obtain S-epoxystyrene isomers and (1R,2S)-epoxyindene with 46 and $73 \%$ ee, respectively, using $m$-CPBA as a oxidant and NMO as a activator at $-78^{\circ} \mathrm{C}$.

Acknowledgment This research was supported by Polish Ministry of Science and Higher Education, Grant No. NN204 131737.

Open Access This article is distributed under the terms of the Creative Commons Attribution Noncommercial License which permits any noncommercial use, distribution, and reproduction in any medium, provided the original author(s) and source are credited.

\section{References}

1. K. Ding, Y. Uozumi, Handbook of Asymmetric Heterogenous Catalysis (Wiley-VCH, Weinheim, 2008)

2. W. Zhang, J.L. Loebach, S.R. Wilson, E.N. Jacobsen, J. Am. Chem. Soc. 112, 7 (1990)

3. R. Irie, K. Noda, Y. Ito, N. Matsumoto, T. Katsuki, Tetrahedron Lett. 31, 7345 (1990)

4. T. Katsuki, Coord. Chem. Rev. 140, 189 (1995)

5. T. Katsuki, J. Molec. Catal. 113, 87 (1996)

6. L. Canali, D.C. Sherrington, Chem. Soc. Rev. 28, 85 (1999)

7. T. Katsuki, Adv. Synth. Catal. 2, 344 (2002)

8. P. McMorn, G.J. Hutchings, Chem. Soc. Rev. 33, 108 (2004)

9. C. Baleizao, H. Garcia, Chem. Rev. 106, 3987 (2006)

10. A. Zulauf, M. Mellah, X. Hong, E. Schulz, Dalton Trans. 39, $6911(2010)$

11. L. Chen, F. Cheng, L. Jia, A. Zhang, J. Wu, N. Tang, Chirality 23, 69 (2011)

12. X. Hu, X. Fu, J. Xu, Ch. Wang, J. Organomet. Chem. 696, 2797 (2011)

13. R. Ji, K. Yu, L.-L. Lou, Z. Gu, S. Liu, J. Inorg. Organomet. Polym. 20, 675 (2010)

14. T.S. Reger, K.D. Janda, J. Am. Chem. Soc. 122, 6929 (2000)

15. K. Smith, C.-H. Liu, Chem. Commun. (Camb). 21, 886 (2002)

16. J.M. Ready, E.N. Jacobsen, J. Am. Chem. Soc. 123, 2687 (2001)

17. J.F. Larrow, E.N. Jacobsen, Y. Gao, Y. Hong, X. Nie, C.M. Zepp, J. Org. Chem. 59(7), 1939 (1994)

18. A. Bukowska, W. Bukowski, Org. Process Res. Dev. 3, 432 (1999)

19. A. Bukowska, W. Bukowski, J. Noworól, J. Appl. Polym. Sci. 101, 1487 (2006)

20. C.T. Dalton, K.M. Ryan, V.M. Wall, C. Bousquet, D.G. Gilheany, Top. Catal. 5, 75 (1998)

21. A. Bukowska, W. Bukowski, React. Funct. Polym. 68, 657 (2008)

22. D.A. Annis, E.N. Jacobsen, J. Am. Chem. Soc. 121, 4147 (1999) 
23. K. Nakamoto, Infrared and Raman Spectra Inorganic and Coordination Compounds (John Wiley and Sons, New York, 1986)

24. E. Pretsch, P. Buhlmann, M. Badertscher, Structure Determination of Organic Compounds (Springer, Verlag, 2009)

25. B. Gong, X. Fu, J. Chen, Y. Li, X. Zou, X. Tu, P. Ding, L. Ma, J. Catal. 262, 9 (2009)

26. R. Ji, K. Yu, L.-L. Lou, Z. Gu, S. Liu, J. Inorg. Organomet. Polym. 20, 675 (2010)

27. X. Hu, X. Fu, J. Xu, Ch. Wang, J. Organomet. Chem. 696, 2797 (2011)
28. B.B. De, B.B. Lohray, S. Sivaram, P.K. Dhal, Tetrahedron Asymmetry 6, 2105 (1995)

29. L. Canali, D.C. Sherrington, H. Deleuze, React. Funct. Polym. 40, 155 (1999)

30. Y. Song, X. Yao, H. Chen, G. Pan, X. Hu, Z. Zheng, J. Chem. Soc. Perkin Trans. 1, 870 (2002)

31. L. Canali, E. Cowan, H. Deleuze, C.L. Gibson, D.C. Sherrington, J. Chem. Soc. Perkin Trans. 1, 2055 (2000)

32. R.I. Kureshy, I. Ahmad, N.H. Khan, S.H.R. Abdi, K. Pathak, R.V. Jasra, J. Catal. 238, 134 (2006) 